\title{
Supercritical fluid extraction of useful compounds from sage
}

\author{
Sameer Al-Asheh", Mamdouh Allawzi, Awni Al-Otoom, Hussein Allaboun, Amani Al-Zoubi
}

Department of Chemical Engineering, Jordan University of Science and Technology, Irbid, Jordan;

*Corresponding Author: alasheh@just.edu.jo

Received 31 May 2012; revised 30 June 2012; accepted 12 July 2012

\begin{abstract}
A qualitative analysis of supercritical fluid extraction (SFE) of the medically useful compound, sage (Salvia officinalis) is presented in this study. Carbon dioxide was used as a supercritical solvent. Effects of operating conditions such as temperature, pressure, and extraction time were investigated. The effect of addition of cosolvents was also studied. The extracted useful compounds were identified and analyzed using GC-MS chromatography. The analysis of the extract obtained by SFE showed certain significant major compounds that are considered medically important. These major compounds are 1R-.alpha.-Pinene, D-Limonene, I-Camphene, and b-Pinene, and Eucalyptol. Although, there was no consistent trend with respect to the effect of the studied parameters on the composition of the extract, the selectivity of these major compounds are dependant on the operating conditions, manily the operating pressure. An increase in the pressure resulted in an increase in herb extraction yield; this is true for certain group of extracts, while the inverse is also true for other group of compounds. The effect of certain cosolvents on the extractability of sage showed a significant improvement of the yield of some particular constituents of sage.
\end{abstract}

Keywords: Supercritical Extraction; $\mathrm{CO}_{2}$; Serge; Ethanol

\section{INTRODUCTION}

Nowadays, there is a significant emphasis on herbs and their uses in medicine as an alternative to chemical drugs; the latest may result in certain side effects. It is known that plants can be used for medicinal purposes long before recorded history. In the early 19th century, when chemical analysis first became available, scientists began to extract and modify useful compounds from plants. Later, chemists began making their own versions of plant compounds, and over time, the use of herbal medicines declined in favor of drugs. Recently, the World Health Organization (WHO) estimated that $80 \%$ of people worldwide rely on herbal medicines for some part of their primary health care [1]. A large number of studies have been conducted to extract valuable ingredients from herbs [2-7]. In many cases, scientists aren't sure what specific ingredient in a particular herb works to treat a condition or illness. Whole herbs contain many ingredients, and they may work together to produce a beneficial effect.

Supercritical Fluid Extraction (SFE) is a process of separating one component (the extractant) from another (the matrix) using supercritical fluid as an extracting solvent. Extraction is usually from a solid matrix, but can also be from liquids as well. SFE can be used as a sample preparation step for analytical purposes, or on a larger scale to either strip unwanted material from a product (e.g. decaffeination) or collect a desired product (e.g. essential oils). Carbon dioxide $\left(\mathrm{CO}_{2}\right)$ is the most commonly used supercritical fluid, sometimes modified by co-solvents such as ethanol or methanol. Extraction conditions for supercritical $\mathrm{CO}_{2}$ are above the critical temperature of $31.04^{\circ} \mathrm{C}$ and critical pressure of 73.8 bar; the addition of modifiers may slightly alter such condition. $\mathrm{CO}_{2}$ is the most commonly used solvent due to its non-toxicity and non flammability properties and its availability in high purity at low cost. It also has good solvent properties for extraction of non-polar components such as hydrocarbons, In order to extract polar components; cosolvent (e.g. ethanol, methanol) is frequently used to raise the solvent power of supercritical $\mathrm{CO}_{2}$. Supercritical fluid extraction has proved effective in the separation of essential oil and its derivatives for use in the food, cosmetics, pharmaceutical and other related industries, producing high-quality oils with commercially more satisfactory compositions than obtained through conventional hydro-distillation [8].

Singh et al. [9] used supercritical carbon dioxide at 
160 bar and 200 bar and both at $40^{\circ} \mathrm{C}$ to extract pepper oil from whole low density Sarawak peppers. Langa et al. [10] studied the optimization of the process parameters for the extraction of Spanish sage essential oil using supercritical fluid in order to obtain extract used for medical applications such as Alzheimer's. Fractions from coriander seeds (Coriandrum sativum) were obtained using supercritical carbon dioxide using a semi-continuous lab-scale process, and tested for antioxidant activity [11]. The extraction of carotenoids from crude palm oil was carried out in a dynamic supercritical fluid extraction [12]; effects of operating pressure and temperature, flow rate of the supercritical $\mathrm{CO}_{2}$, and sample size of feed used on the solubility of palm carotenoids were investigated.

Sage (Salvia officinalis) is a popular kitchen herb and is a member of the mint (Labiatae) family. It has been used in a variety of food preparations since ancient times. From its Latin name, "Salvia" meaning to cure and "Officinalis" meaning medicinal, sage has a historical reputation for promotion of health and treatment of ailments. The major components of sage to which its traditional uses can be attributed, are volatile oil and tannins. The oil of a related species, salvia lavandulifolia, is being investigated for symptomatic treatment of Alzheimer's disease. However, at present, there is a lack of well-designed clinical studies investigating the reputed effects of sage. Sage oil contains high concentrations of thujone, a toxic ketone, and should not be ingested [9].

The main objective of this study is to qualitatively investigate the extractactability of useful compounds from sage herb via the SCFE technique. The effects of different parameters and operating conditions such as pressure, temperature and detention time on the type and yield of useful compounds will be studied. The useful compounds are believed to include volatile oils, tannins, mucilage, alkaloids and bitters. It is aimed to increase the selectivity of extraction of such essential components by using the supercritical extraction technique with $\mathrm{CO}_{2}$ as a solvent, which is maintained under supercritical conditions until the required time is reached. In addition, a polar aprotic solvent (acetone) and a non-polar solvent (hexane) were used in some of the experiments to investigate the effect of cosolvent on the extractability of sage.

\section{MATERIALS AND METHODS}

\subsection{Materials}

The sage herbs chosen for this study were collected from a home garden as leaves. After harvesting, the leaves were separated and washed under tap water. Leaves were dried at $40^{\circ} \mathrm{C}$ in a ventilated drying oven for $24 \mathrm{~h}$ until constant mass and then stored at ambient temperature in the dark place. To avoid degradation, the dried plant material was ground just before extraction. The dried plant leaves were ground in a blender (Panasonic, Malaysia) for $10 \mathrm{~s}$ to produce powder with an approximate size of about $0.6 \mathrm{~mm}$. Carbone dioxide (purity $99.99 \%$ ), contained in a diptube cylinder, was purchased from the market. Ethanol (EtOH, 99.5\%, analytical grade) was also used as a cosolvent for some of the experiments.

Supercritical $\mathrm{CO}_{2}$ was obtained by using SFT-10 Supercritical Fluid Pump. The SFT-10 is a high precision carbon dioxide pump designed to deliver liquid carbon dioxide at pressures up to $10,000 \mathrm{psi}(68.9 \mathrm{MPa})$. It can be used to deliver both liquid and supercritical $\mathrm{CO}_{2}$ to new and existing SFE equipment. It has a dual piston pump which rapidly produces the pressures required for supercritical fluid and other high pressure applications.

\subsection{Apparatus}

The extraction apparatus is installed as shown in Figure 1. A risk assessment for proposed experimental procedures was determined. The apparatus was tested at a high pressure reaching 4000 psi without any leak detected and safety steps were considered during the experimental tests.

\subsection{Experimental Procedure}

Supercritical fluid extraction (SCFE) tests were carried out in a batch mode. A $10 \mathrm{~g}$ weighted sample of sage herb was inserted into the $300 \mathrm{~cm}^{3}$ stainless steel fixed bed vessel. The fixed-bed sage was brought to steady state operation of the required pressure and temperature; this was achieved by heating using an electrical heater in a water bath and an SFT-10 Supercritical Fluid Pump. The bed was kept at the desired temperature and pressure for about 15 minutes.

Carbon dioxide SCF $\left(\mathrm{CO}_{2}\right)$ was fed into the reactor continuously with a supercritical fluid pump at flow rate of $100 \mathrm{ml} / \mathrm{min}$ and a pressure in the range of $1250-2500$ psi. After the desired parameters (temperature and pressure) were reached, the pump was kept running for about 15 minutes at the same pressure. The product was collected in a beaker containing ethanol through the valve located at the joint with the outlet of the reactor. The ethanol acts as a trap to the compound that was extracted from the plant leaves and carried out with $\mathrm{CO}_{2}$. When the $\mathrm{CO}_{2}$ that carries the extract material leaves the stainless steel fixed bed reactor, it converts to its gaseous state and the extract material stay in the ethanol and $\mathrm{CO}_{2}$ disappeared. The obtained samples were placed in a glass container for further analysis.

\subsection{Gas Chromatography-Mass Spectrometry (GC-MS) Analysis}

The collected samples were analyzed using the Gas 


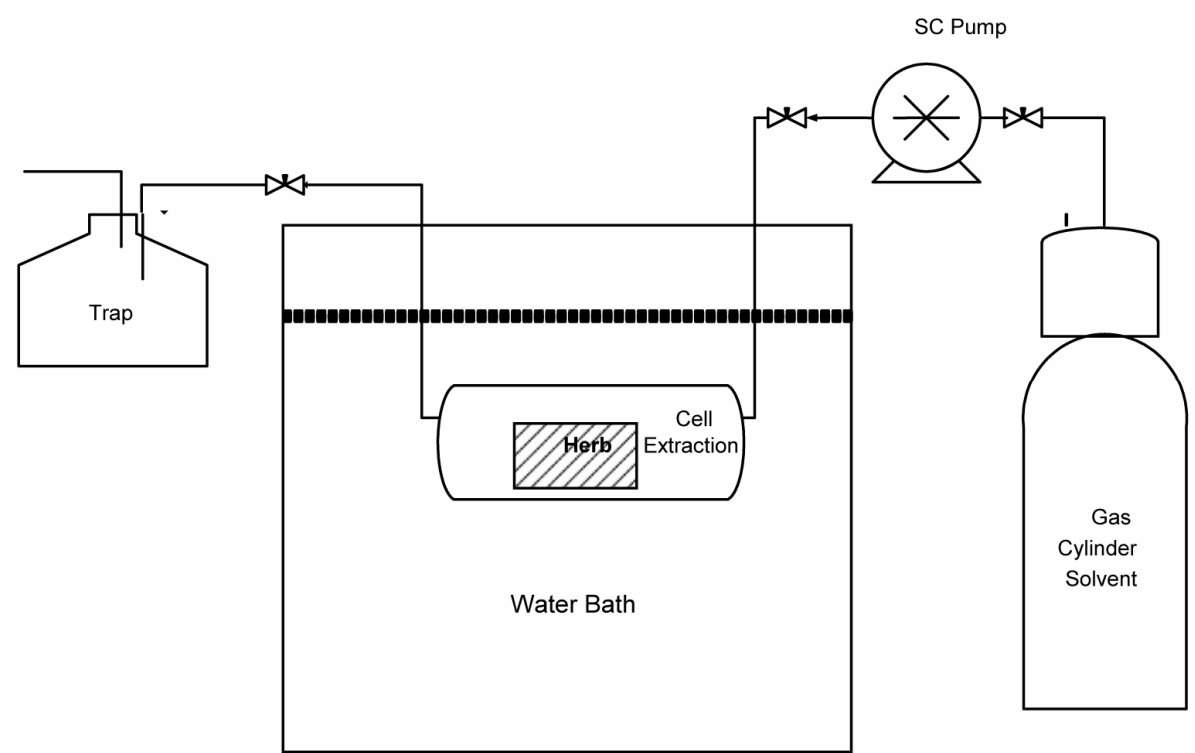

Figure 1. Schematic diagram for the supercritical experimental setup.

chromatography-mass spectrometry (GC-MS) method. The samples were analyzed using Varian 450-GC (VARIAN, British). One ml of sample was taken and put in a $5 \mathrm{ml} \mathrm{GC}$ vial, this sample was inserted in an agitator and kept at a temperature of $70^{\circ} \mathrm{C}$ for 5 minutes to convert the liquid sample to a volatile one. An injector (CAR/PDMS) was then inserted into this vial for about 30 minutes to extract all volatile compounds using a technique called solid phase micro extraction. The sample was then transferred to the injector port and the extracted compound was released into this port. The temperature of the port was $250^{\circ} \mathrm{C}$; this is in order to maintain the sample in its volatile state. These separated compounds were then analyzed using Varian 320-MS (VARIAN, British); this detector uses the molecular weight with a scan range of 50 - 550 amu to specify the extracted compound.

\section{RESULTS AND DISCUSSION}

Analysis of sage herb extract using GC-MS showed that there are 41 compounds with different prortions depending on the extraction conditions. Only major compounds will be indicated in the following results. These are illustrated in Table $\mathbf{1 .}$

The analysis of the extract showed certain significant major compounds such as 1R-.alpha.-Pinene (35\%), DLimonene (39\%), 1-Camphene (12\%), and b-Pinene (6\%), and Eucalyptol. These compuonds have important applications in the pharmaceutical industry. For example, $1 \mathrm{R}$-.alpha.-Pinene is a main raw material used in the perfume industry. Also, it is an essential raw material for the fine chemical industry [14]. Because it is a solvent for cholesterol, D-limonene has been clinically used to dissolve cholesterol-containing gallstones. It has also been used to relieve heartburn due to its potential for gastric acid neutralization and its support for healthy peristalsis. D-limonene has well-established chemopreventive activity against many types of cancers [15].

The remaining compouds from the extract have small proportions, however, these compounds have an important role in the pharmaceutical industry. For example, the cineole-based oil in eucalyptol is used as a component in pharmaceutical preparations to relieve the symptoms of influenza and colds, in products like cough sweets, lozenges, ointments and inhalants [16]. Also Caryophyllene is considered to be anaesthetic, antifungal, antiseptic and antibacterial [17].

\subsection{Effect of Operating Parameters on the Extraction by SCF}

\subsubsection{Effect of Extracting Pressure}

Figure 2 shows sage extracts at pressures 1750, 2000, and 2500 psig, respectively, while maintaining other parameters at fixed values. It can be seen that the effect of pressure is noticable; since some of the compounds appeared at certain pressure and dissappeared at other pressure levels. For example, Thujone could be extracted at a pressure of 2000 psig, but could not be detected at other extraction pressures. Pressure can also affect the amount of compounds being extracted; i.e. the concentration of some compounds increases with increasing extraction pressure, while for other compounds decreases with increasing extraction pressure.

The explanantion of such effect of pressure can be attributed to the solvent power for extraction. During their study on extraction of Thymbra spicata oil using 


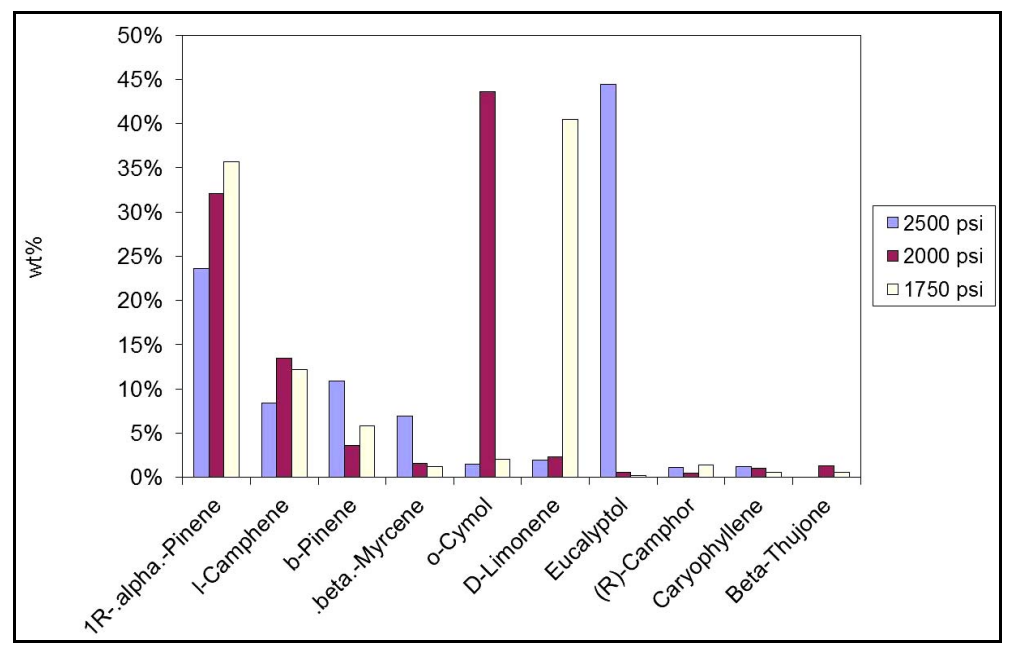

Figure 2. The effect of SCF operating pressure on the quality of extract. Temperature $=40^{\circ} \mathrm{C}$, time $=15 \mathrm{~min}$.

Table 1. Most dominant compounds of sage after SCF extraction.

\begin{tabular}{|c|c|c|c|c|}
\hline \multicolumn{3}{|c|}{ SCF extraction conditions } & \multirow{2}{*}{ Most dominant constituent of sage } & \multirow{2}{*}{ wt $\%$} \\
\hline T time, min & Temperature, ${ }^{\circ} \mathrm{C}$ & Pressure, psi & & \\
\hline 15 & 70 & 1750 & D-Limonene & 39.4 \\
\hline \multirow{2}{*}{15} & \multirow{2}{*}{70} & \multirow{2}{*}{2000} & o-Cymol & 41.1 \\
\hline & & & 1R-.alpha.-Pinene & 30.2 \\
\hline \multirow{2}{*}{15} & \multirow{2}{*}{70} & \multirow{2}{*}{2500} & Eucalyptol & 43.9 \\
\hline & & & 1R-.alpha.-Pinene & 23.3 \\
\hline 120 & 40 & 1500 & Eucalyptol & 48.4 \\
\hline \multirow{2}{*}{120} & \multirow{2}{*}{50} & \multirow{2}{*}{1500} & Supraene & 33.8 \\
\hline & & & Eucalyptol & 29.1 \\
\hline \multirow{4}{*}{120} & \multirow{4}{*}{60} & \multirow{4}{*}{1500} & Squalene & 28.4 \\
\hline & & & Eucalyptol & 26.2 \\
\hline & & & Supraene & 13.1 \\
\hline & & & 1R-.alpha.-Pinene & 13.1 \\
\hline \multirow{2}{*}{120} & \multirow{2}{*}{70} & \multirow{2}{*}{1500} & 1R-.alpha.-Pinene & 39.9 \\
\hline & & & D-Limonene & 31.6 \\
\hline \multirow{2}{*}{45} & \multirow{2}{*}{70} & \multirow{2}{*}{1500} & 1R-.alpha.-Pinene & 32.9 \\
\hline & & & Eucalyptol & 30.6 \\
\hline 60 & 70 & 1500 & Eucalyptol & 48.8 \\
\hline 120 & 70 & 1500 & Eucalyptol & 54.7 \\
\hline
\end{tabular}

supercritical fluid extraction, Sonsuzer et al. [18] found that while pressure was increasing, yield increased. The authors attributed such trend to the increase in the solvent power of the supercritical $\mathrm{CO}_{2}$ with increasing pressure. Menaker et al. [19] identified and characterized the supercritical extracts of certain herbs and found that the decrease in the yields of the extracts of lovage is due to the increase in pressures.

At constant temperature, the density of the solvent increases with an increase in pressure, however, the 
vapour pressure of the solute decreases with an increase in pressure. At elevated pressure, the magnitude of such a solute vapour pressure change becomes smaller and the density change becomes more effective and can easily overcome the effect of the solute vapour pressure change on the extraction rate. This behaviour was indicated earlier by Marentis [20].

\subsubsection{Effect of Extraction Temperature}

Another set of experiments were conducted in order to study the effect of temperature on the supercritical extraction of sage extracts. In this part, all other parameters were fixed while the temperature, which was increased from $40^{\circ} \mathrm{C}$ to $70^{\circ} \mathrm{C}$. Unlike normal solvent extraction, it was essential not to reach high temperature of in order to reduce the thermal degradation of important constituents of the extract.

During supercritical carbon dioxide extraction, the change in temperature affects the density of carbon dioxide, the volatile property of the analytes, and the desorption of the analytes from the herb matrices. At higher temperature, the analytes become more volatile but the supercritical carbon dioxide density decreases, as shown by Yang et al. [21]. Generally, at high pressure, the influence of temperature on the solubility is more pronounced than the influence of supercritical carbon dioxide density variation; while at low pressure, the effect of density becomes more pronounced, as found by Kiriamiti et al. [22]. The increase in extraction efficiency with increasing process temperature can be dependent on the molecular mass, which is related to the binary diffusion coefficient of solute molecules in supercritical carbon dioxide, as indicated Span and Wagner [23]. The fluid mass transfer coefficient and the effective diffusion coefficient increase with temperature owing to the increase in the binary molecular diffusivity.

Supercritical fluid extraction is basically a desorption process. It is reported that the desorption kinetic constant increases with temperature [24]. In addition, analytes can be strongly bound to the real-world samples, and a certain amount of energy is required for the extraction system; thus at high temperatures the rate of the desorption process greatly increases [21]. This is because the carbon dioxide density reduces significantly when the temperature increases. The density of carbon dioxide is the predominant factor for the dissolution of organic molecules in supercritical carbon dioxide. The density of carbon dioxide determines strongly the number of interactions between carbon dioxide and the solute molecules. If sufficient interactions occur, the cohesive forces between the individual solute molecules are broken down rapidly and solubilization will be enhanced. Therefore, solubilization of solute in carbon dioxide is a function of the molecular mass of the solute and the level of interaction between carbon dioxide and the solute molecules [25]. In principle, at constant pressure, the density of the solvent decreases with an increase in temperature; while the vapor pressure of the solute increases with an increase in temperature [26]. Thus, the change in solvent density becomes more effective and can easily overcome the effect of the solute vapor pressure variation on the extraction rate [27]. Such an explanation was used for supercritical carbon dioxide extraction of poly-cyclic aromatic hydrocarbons from environmental samples as reported by Yang et al. [21], and can also be applied to the results of this work. The results showed that the desorption rate decreases with the increase of temperature indicating the endothermic nature of such process, and thus, lower yields are obtained at higher temperatures.

Since the extraction of solute from herb matrices is basically a desorption process, the increase of desorption kinetic constant leads to an increase of the extraction rate and the extract yield. However, a further increase in temperature reduces the extract yield.

The effect of extraction temperature on the concentration of some of the extraction compounds is shown in Figure 3. It is seen that as the extraction temperature increases, the concentration of sage extract decreases. Similar behavior was noticed by Sonsuzer et al. [18], who reported an inverse temperature effect on the solubility of the volatile oil compounds; i.e. solvent power of the supercritical fluid. However, Ge et al. [28] reported that at high temperature and pressure, the extraction rate and yield are higher when using supercritical carbon dioxide as well as carbon dioxide and ethanol mixture as cosolvent to extract and rographolide. Thus, there is no specific trend for the effect of temperature on supercritical extraction.

Eucalyptol is one of the most important constituents of sage, it has wide range of uses in medicinal and industrial applications. The concentration of Eucalyptol has shown a decrease with increasing the extraction temperature as shown in Figure 4. Therefore, to achieve the highest concentration of this valuables product, it is recommended to use the lowest temperature possible above the critical temperature.

\subsubsection{Effect of Extraction Time}

A set of experiments were also conducted to study the effect of contact time on the supercritical extraction. In this part, all the parameters were fixed except the extraction time which ranged from $45 \mathrm{~min}$ to $180 \mathrm{~min}$; the results are shown in Figure 5 at $\mathrm{CO}_{2}$ flow rate of 100 $\mathrm{ml} / \mathrm{min}$.

The extraction time is an important factor affecting the extraction processes as certain compounds seem to not appear at a long period of extraction time. Thus, there might be an optimum extraction time need to obtain 


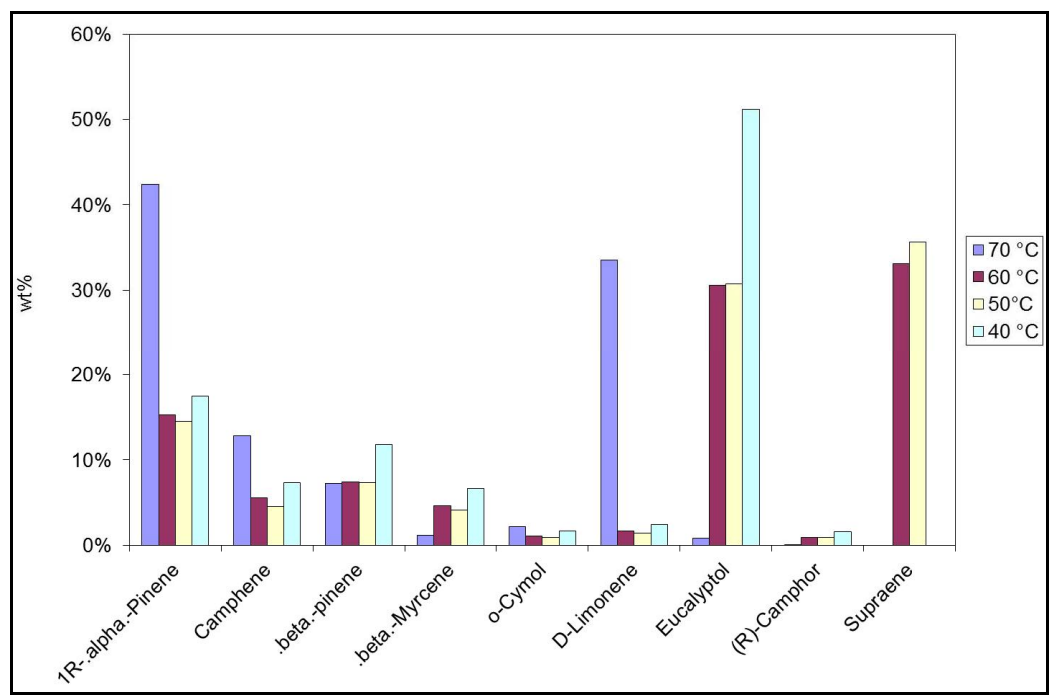

Figure 3. The effect of SCF operating temperature on the quality of extract. $\mathrm{P}=$ $1500 \mathrm{psi}$, time $=70 \mathrm{~min}$.

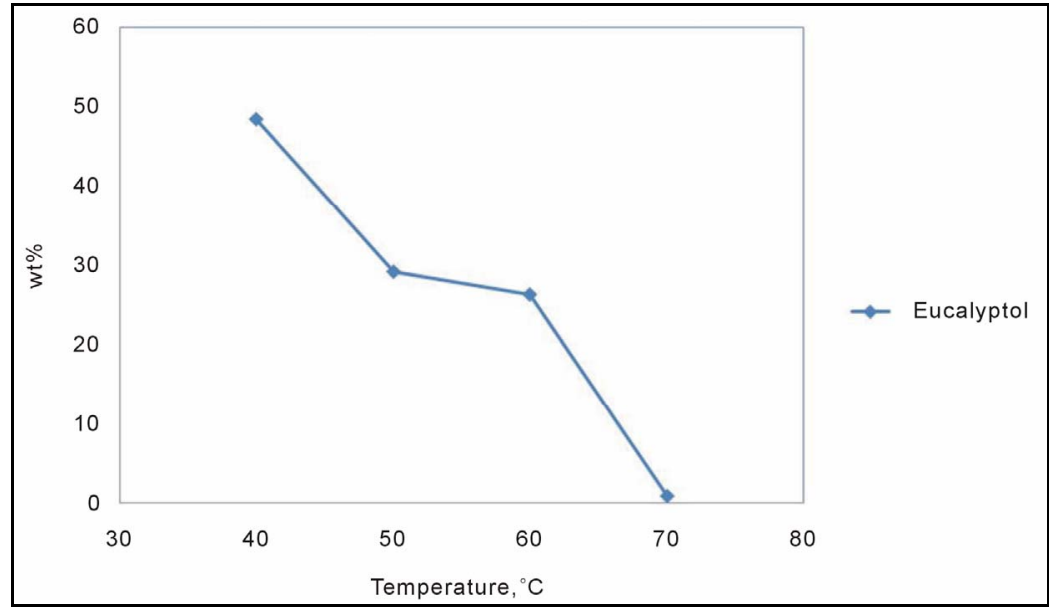

Figure 4. Effect of SCF extraction temperature on the yield of Eucalyptol. P= $1500 \mathrm{psi}$, time $=120 \mathrm{~min}$.

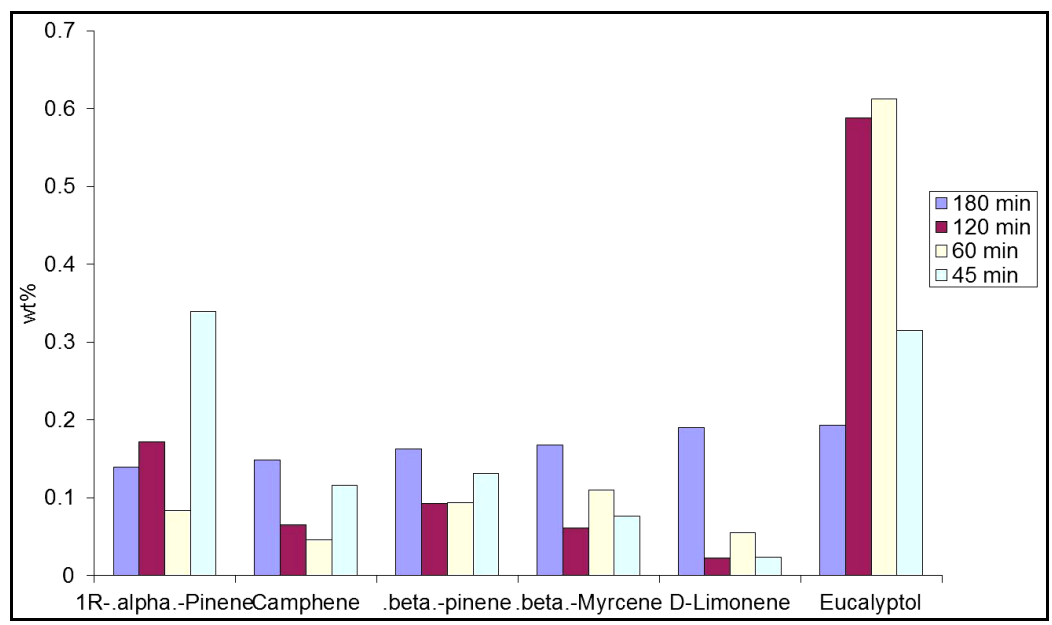

Figure 5. Effect of the SCF residence time on the quality of extract. $\mathrm{P}=1500 \mathrm{psi}$, $\mathrm{T}=40^{\circ} \mathrm{C}$. 
compounds with optimum concentration. In other words, it is possible that if extraction is allowed for a longer period of time, some compounds might form and convert to other compounds. Similar findings have been concluded elsewhere; for example the concentration of monoterpenes increased as extraction time and pressure increased, which was due to the enhanced leaching of harder compound to extract substances [18].

The results in this study have shown that there is no distinct effect of any of the studied parameters on the concentrations of main constituents of sage. However, shows the most dominant compounds of sage resulting from the SCF extraction trials.

Two cosolvents were utilized in order to study the effect of these solvents on the extraction quality of sage; these were a polar aprotic solvent, acetone, and a nonpolar solvent, hexane. As shown in Table 2, the acetone has helped increasing the contents of Eucalyptol to around $70 \%$, which is considered a significant increase at low temperature and pressure. This can be explained by the polarity nature of Eucalyptol. On the other hand, acetone has helped in increasing the pinene compound, and it helped in the extraction of a new compound; namely 3 -carene, which is an important bone in the production of many biologically active compounds [29].

\section{CONCLUSION}

Supercritical fluid extraction can be used efficiently in the extraction of valuable ingredients from sage herbs. Four parameters were examined in this study; namely pressure, temperature, contact time, and cosolvents. These can be optimized for supercritical extraction of certain required compounds from the herb under consideration. An increase in the pressure resulted in an increase in herb extraction yield; this is true for certain group of extracts, while the inverse is also true for other group of compounds. The extraction yield decreases with the increase in extraction temperature. Contact time is an important parameter in the extraction process; it can affect the extraction yield of certain compounds. The use of a polar cosolvent has helped in the increase of the

Table 2. Main compounds of SCF extraction of sage using cosolvents $(0.5 \mathrm{wt} \%) . \mathrm{T}=40^{\circ} \mathrm{C}, \mathrm{P}=1500$ psi.

\begin{tabular}{cccc}
\hline \multicolumn{2}{c}{ Acetone Cosolvent } & \multicolumn{2}{c}{ Hexane Cosolvent } \\
\hline Compound & $\mathrm{wt} \%$ & Compound & $\mathrm{wt} \%$ \\
3-Carene & 9.4 & 3-Carene & 18.2 \\
beta.-pinene & 13.8 & .beta.-pinene & 19.2 \\
b-Pinene & 5.8 & beta.-Phellandrene & 7.4 \\
Eucalyptol & 71.0 & Eucalyptol & 55.2 \\
\hline
\end{tabular}

yield of polar compounds in sage, mainly eucalyptol.

\section{REFERENCES}

[1] University of Maryland (2010) Medical centre. http://www.umm.edu/altmed/articles/herbal-medicine-000 $\underline{351 . h t m}$

[2] Laurence, M.H. and Christopher, J.M. (1998) Experimental organic chemistry: Principles and practice, 2nd Edition, Blackwell Science Ltd.

[3] Durling, N.E., Catchpole, O.J., Grey, J.B., Webby, R.F., Mitchell, K.A. and Yeap, F.L. (2007) Extraction of phenolics and essential oil from dried sage (Salvia officinalis) using ethanol-water mixtures. Food Chemistry, 101, 1417-1424. doi:10.1016/j.foodchem.2006.03.050

[4] Areias, F., Valentao, P., Andrade, P.B., Ferreres, F. and Seabra, R.M. (2000) Flavonoids and phenolic acids of sage: Influence of some agricultural factors. Journal of Agricultural and Food Chemistry, 48, 6081-6084. doi:10.1021/jf000440+

[5] Guenther, E. (1974) The essential oils. Van Nostrand, New York.

[6] Nassr-Allah, A., Aboul-Enein, A.M., Aboul-Enein, K.M., Lightfoot, D.A., Cocchetto, A. and El-Shem, H.A. (2009) Anti-cancer and anti-oxidant activity of some Egyptian medicinal plants. Journal of Medicinal Plants Research, 3, 799-808.

[7] Jimenez-Carmona, M.M., Ubera, J.L. and Luque De Castro, M.D. (1999) Comparison of continuous subcritical water extraction and hydro distillation of marjoram essential oil. Journal of Chromatography, 855, 625-632. doi:10.1016/S0021-9673(99)00703-7

[8] Ehlers, D., Nguyen, T., Quirin, K.W. and Gerard, D. (2001) Analysis of essential basil oils- $\mathrm{CO}_{2}$ extracts and steam-distilled oils. Deutsche Lebensmittel-Rundschau, 97, 245-250.

[9] Singh, H., Hasan, M. and Kang, L.J. (2003) Supercritical carbon dioxide extraction of Sarawak black pepper oil. Internal Report, Department of Chemical Engineering, University of Malaya.

[10] Langa, E., Della Porta, G., Palavra, A.M.F, Urieta, J.S. and Mainar A.M. (2009) Supercritical fluid extraction of Spanish sage essential oil: Optimization of the process parameters and modeling. The Journal of Supercritical Fluids, 49, 174-181. doi:10.1016/j.supflu.2008.12.007

[11] Yepez, B., Espinosa, M. and Bolanos, L.G. (2002) Producing antioxidant fractions from herbaceous matrices by supercritical fluid extraction. Fluid Phase Equilibria, 194-197, 879-884. doi:10.1016/S0378-3812(01)00707-5

[12] Chiew, W.P., May, C.Y., Ngan, M.A. and Hock, C.C. (2005) Supercritical fluid extraction of palm carotenoids. American Journal of Environmental Sciences, 1, 264-269. doi:10.3844/ajessp.2005.264.269

[13] Joanne, B.J., Linda, A.A. and Phillipson, J.D. (2007) Herbal medicines. Pharmaceutical Press, Germany.

[14] Honye (2010) Honey Chemical Co. 
http://www.hongyechemical.com/e pinene.htm

[15] Sun, J.D. (2007) D-Limonene: Safety and clinical applications. Alternative Medicine Review, 12, 259-264.

[16] Wikipedia (2010) Eucalyptus_oil. http://en.wikipedia.org/wiki/Eucalyptus oil

[17] Deba, F., Xuan, T.D., Yasuda M. and Tawata, S. (2008) Chemical composition and antioxidant, antibacterial and antifungal activities of the essential oils from Bidens pilosa Linn. var. Radiata. Food Control, 19, 346-352. doi:10.1016/j.foodcont.2007.04.011

[18] Sonsuzer, S., Sahin, S. and Yilmaz, L. (2004) Optimization of supercritical $\mathrm{CO}_{2}$ extraction of Thymbra spicata oil. Journal of Supercritical Fluids, 30, 189-199. doi:10.1016/j.supflu.2003.07.006

[19] Menaker, A., Kravets, M., Koel, M. and Orav A. (2004) Identification and characterization of supercritical fluid extracts from herbs. Comptes Rendus Chimie, 7, 629-633. doi:10.1016/j.crci.2004.03.005

[20] Marentis, R.T. (1988) Steps to developing a commercial supercritical carbon dioxide processing plant. In: Carpentier, B.A. and Sevenants, M.R., Eds., Supercritical Fluid Extraction and Chromatography, American Chemical Society, Washington DC. doi:10.1021/bk-1988-0366.ch007

[21] Yang, Y., Gharaibeh, A., Hawthorne, S.B. and Miller, D.J. (1995) Combined temperature \& modifier effects on supercritical $\mathrm{CO}_{2}$ extraction efficiencies of polycyclic aromatic hydrocarbons from environmental samples. Analytical Chemistry, 67, 641-646. doi:10.1021/ac00099a023

[22] Kiriamiti, H.K., Rascol, E., Marty, A. and Condoret, J.S. (2002) Extraction rates of oil from high oleic sunflower seeds with supercritical carbon dioxide. Chemical Engineering and Processing, 41, 711-718.
doi:10.1016/S0255-2701(01)00191-X

[23] Span, R. and Wagner, W. (1996) A new equation of state carbon dioxide covering the region from triple-point temperature to $1100 \mathrm{~K}$ at pressure up to $800 \mathrm{MPa}$. Journal of Physical and Chemical Reference Data, 25, 15091596. doi:10.1063/1.555991

[24] Lucas, S., Calvo, M.P., Palencia, C. and Cocero, M.J. (2004) Mathematical model of supercritical $\mathrm{CO}_{2}$ adsorption on activated carbon: Effect of operating conditions and adsorption scale-up. Journal of Supercritical Fluids, 32, 193-201. doi:10.1016/j.supflu.2004.02.008

[25] Baysal, T. and Starmans, D.A.J. (1999) Supercritical carbon dioxide extraction of carvone and limonene from caraway seed. Journal of Supercritical Fluids, 14, 225234. doi:10.1016/S0896-8446(98)00099-0

[26] Jossi, J.A., Stiel, L.I. and Thodos, G. (1962) The viscosity of pure substances in the dense gaseous and liquid phases. AIChE Journal, 8, 59-62. doi:10.1002/aic.690080116

[27] Roy, B.C., Goto, M., Kodama, A. and Hirose, T. (1996) Supercritical $\mathrm{CO}_{2}$ extraction of essential oils and cuticular waxes from peppermint leaves. Journal of Chemical Technology and Biotechnology, 67, 21-26. doi:10.1002/(SICI)1097-4660(199609)67:1<21::AID-JC TB522>3.0.CO;2-0

[28] Ge, F.H., Lin, X.X., Huan, X.F., Shi, Q., Liang, B., Li J. and Zhong, G. (2002) Study on extraction of active ingredients from Andrographis paniculata using orthogonal experiment with supercritical carbon dioxide. Journal of Chinese Medical Materials, 25, 101-102.

[29] Fliur, Z., and Andrei, V.M. (2006) Use of monoterpenes, 3 -carene and 2-carene, as synthons in the stereoselective synthesis of 2,2-dimethyl-1,3-disubstituted cyclopropanes. Tetrahedron, 62, 9-29. doi:10.1016/j.tet.2005.09.001 